\title{
Pilot Scale Demonstration of Carbon Mineralization in Processed Kimberlite
}

\author{
E.R. WYNANDS ${ }^{1 *}$, E. ALBAN ${ }^{1}$, G.M. DiPPLE ${ }^{1}$, A. SHAW ${ }^{2}$, \\ S. MCLEAN ${ }^{3}$ \\ ${ }^{1}$ Bradshaw Research Initiative for Minerals and Mining, \\ University of British Columbia, Vancouver, BC, V6T \\ 1Z4, Canada (*correspondence: ewynands@eoas.ubc.ca) \\ ${ }^{2}$ Lorax Environmental Services Ltd., Vancouver, BC, V6J \\ 3H9, Canada (alison.shaw@lorax.ca) \\ ${ }^{3}$ De Beers Canada Inc., Calgary, AB, T2E 6Z8, Canada \\ (Sarah.McLean@debeersgroup.com)
}

Processed kimberlite has the potential to sequester $\mathrm{CO}_{2}$ via enhanced weathering processes into magnesium carbonate minerals. In order to accelerate carbon mineralization, increasing the supply rate of $\mathrm{CO}_{2}$-enriched gases necessitates flue gas injection. Fine grain sizes enable rapid reactivity, while coarse grain sizes provide the permeability necessary for economical gas injection. The permeability regime has been mapped out for various coarse and fine processed kimberlite blends. This has enabled lab-scale experiments of simulated flue gas injection through idealized blends to understand reaction rates, coarse phase reactivity, and the challenges of scale increases. Subsequently, two meter-scale experiments were conducted this summer on site at Gahcho Kué Mine, NWT, using $500 \mathrm{~kg}$ of processed kimberlite. The first experiment injected simulated flue gas into mixed coarse and fine kimberlite packed into a six-meter pipe. $\mathrm{CO}_{2}$ breakthrough for unreactive material would have occurred after 90 minutes. No $\mathrm{CO}_{2}$ was observed exiting the pipe for 44 hours, demonstrating effective reactivity of the processed kimberlite under field conditions. The second experiment evaluated gas injection in two dimensions and the use of fines to trap injected gas. Analyses of the inorganic carbon from reacted samples confirm sequestration into carbonate minerals. Insights from these field trials are progressing the design of industrial-scale experiments, to be performed in the summer of 2020. The objective is to demonstrate that at the mine scale processed kimberlite can effectively and economically capture carbon, thereby reducing mine emissions. 